\title{
A study into the psycho-socio-demographic profile and suicidal intent in the persons making suicide attempt : Search for a distinctive group
}

\author{
Subir Bhattacharjee1, Amit Bhattacharyya ${ }^{2}$, Om Prakash Pingh ${ }^{3}$ \\ Institute of Psychiatry, IPGME \& R, Kolkata. E mail - subir.jeet@gmail.co ${ }^{1}$, BMCH, Burdwan \\ E mail - amit.bhattacharya07@gmail.com² \\ NRSMCH, Kolkata. E mail - opsingh.nm@gmail.com ${ }^{3}$
}

\section{ABSTRACT :}

Introduction : Epidemiological studies simultaneously investigating the combined effects of psychiatric and psychosocial risk factors for suicide are sparse. Presently no distinctive grouping has been done combining the suicide intent and lethality of attempt though there are significant variations in psycho-socio-demographic character within the persons making suicide attempt.

Aims : To study the psycho-socio-demographic profile, suicide intent and lethality of attempt in survivors of suicide attempt and finally to categorize them in distinct groups by two dimensions suicide intent and lethality of suicide attempt.

Design : Cross-sectional study.

Methods and Material : Two hundred patients who attempted suicide were evaluated by a psychiatrist. The data was recorded for socio demographic variables, psychiatric disorder, suicide intent and for lethality of attempt. Groupings were done first by single dimension, suicide intent, then by two dimensions, suicide intent and lethality of attempt. Two procedures were then compared statistically.

Results : The mean age of the study population was 26.36 years, mostly female (50.5\%), housewives $(35.5 \%)$ and students $(10 \%)$, from nuclear family $(55.5 \%)$, with no psychiatric disorder (29\%). Organophophorus poisoning (79.5\%) was the principal mode of suicide attempt, out of problem with primary support group (89.5\%). Grouping was more significant when based on combining two dimensions, suicide intent and lethality of attempt, rather than only single dimension, suicide intent.

Conclusions : Both suicide intent and lethality of suicide attempt are important dimensions to categorize suicide attempters. There exists four groups and they are different in psycho-sociodemographic profile.

Declaration of interest - None.

Key-words : Suicide, Suicide intent, Lethality, Deliberate self harm

\section{INTRODUCTION :}

Suicide is derived from the Latin word self murder. It is a fatal act that represents the person's wish to die. Suicide is an important issue in the Indian context.

Contributor for Correspondence :

Dr. Subir Bhattacharjee, RMO cum Clinical Tutor

Dept. of Psychiatry, IPGME \& R, Kolkata

Email -subir.jeet@gmail.com
More than one lakh (one hundred thousand) lives are lost every year to suicide in our country. The true magnitude of suicide as a public health problem is not clear in India. In the last two decades, official figures of suicide rate in India have increased from 7.9 to 10.3 per 100,000 . ${ }^{1}$ Epidemiological studies simultaneously investigating the combined effects of psychiatric and psychosocial risk factors for 
suicide are sparse. ${ }^{2}$ Variations in suicide risk factors in different cultures and periods are $\mathrm{known}^{3,4}$ and it is acknowledged that more research is required, especially from developing nations.

Stenge $l^{6}$ identified differences between people who completed suicide and who attempted suicide but survived. He said that a degree of suicidal intent was present in both groups and those who survived were 'failed suicide'. Kessel and Grossman ${ }^{7}$ found that most of those who 'attempted suicide' had performed their act in the belief that they were comparatively safe; that even in the heat of the moment they were aware that they would survive; and that they did not really want to commit suicide. Based on this reasoning, Kessel and Grossman ${ }^{7}$ proposed that 'attempted suicide' be replaced by 'deliberate self-poisoning' and 'deliberate selfinjury'. Morgan ${ }^{8}$ suggested the term deliberate self-harm (DSH) to provide a single term covering deliberate self-poisoning and deliberate self-injury. Here suicide intent is taken as the only determining dimension to define DSH group.

Presently there has been no differentiation within Deliberate Self Harm (DSH) group - i.e. those who committed a lethal attempt but survived due to medical care and those who committed a nonlethal attempt and survived. But there is difference in repetition rate of these two groups in future. Unfortunately it is not possible to predict suicide. The best that can be done is to identify and define the group at risk. ${ }^{5}$

The problem of denoting the seriousness of an individual's attempt or desire to end his life was handled by conceptualizing intent as a dimension. Beck hypothesized that by taking into account the suicide attempter's preconceptions of the lethality of his act, they could demonstrate that suicidal intent is an important determinant of medical lethality.

In recent years a number of efforts have been made to introduce greater conceptual clarity and order into the study of suicidal behaviors. More recently, a system of classification was prepared by the Committee on Classification and Nomenclature, Center of Studies of Suicide Prevention, National Institute of Mental Health. This committee classified suicidalbehaviorsinto threemajorgroups:completed suicides, attempted suicides, and suicidal ideation.
9 Study by Jain and his colleagues' supports the conceptual usefulness of the dimension of intent as a qualifying term in designating attempted suicides and supports the validity of the Suicidal Intent Scale as a measure of the seriousness of a suicide attempt. At the same time, the study confirms the low validity of medical lethality as a measure of the seriousness of intent, since in the majority of the cases the patient inaccurately conceived the lethality of his act 10 Accuracy of expectations about the likelihood of dying moderates the relationship between suicide intent and medical lethality. ${ }^{11}$

This aspect of suicidal behavior points to lack of clarity in the differentiation of definitions of completed suicide and attempted suicide (DSH). Due emphasis should be given on the intention, lethality and rescuability in killing oneself to differentiate between attempters (DSH) and completers. ${ }^{12}$

\section{SUBJECTS AND METHODS :}

This cross-sectional study was conducted in the Department of Psychiatry of a large teaching hospital, having major drainage from rural districts and also near urban areas, in the year 2010-2011 after approval by local Ethical Committee. All the patients who got admission in this hospital in various departments for suicide attempt, were referred to psychiatry department after discharge for psychiatric evaluation and future management. Those patients were included in this study and related information was also collected from their attendant.

Subjects - $200(n=200)$ consecutive patients, of both sexes, were interviewed and taken as subject, fulfilling the following inclusion criterion -1) Age $\geq 15$ years, 2) Willing to participate and giving valid informed consent. Those with Mental retardation were excluded from the study.

Procedure - The nature and aims of the study was fully explained to the patient and their attendant. Written informed consent was taken before the interview. Relevant data were then collected in especially designed semi structured socio demographic proforma documenting socio demographic variables and in Beck Suicide Intent Scale questionnaire for measuring suicide intent. 
A study into the psycho-socio-demographic profile and suicidal intent

We also included questions on stressor (according to Axis IV of DSM IV TR diagnosis) in the proforma. Lethality of suicide attempt (Lethal or Non-lethal) was assessed from emergency report on admission, based on clinical conditions of the patient during admission. Lethality of attempt was assessed after the completion of the interview to prevent interviewer bias on assessing suicide intent. Psychiatric diagnosis was made according to DSM IV TR diagnostic criterion.

\section{RESULT :}

The mean age of the study population was 26.36 years and median age was 25 years. Females (50.5\%) slightly outnumbered males $(49.5 \%)$ with Male: Female ratio of 99:101. Most of the subjects were Hindus (83\%). Educational status showed most of the subjects were illiterate (39.5\%), next had middle school education $(34.5 \%)$ and $6.5 \%$ were educated up to high school. Majority of the patients were housewives (35.5\%), next were semi skilled workers $(33 \%)$. Notably students $(10 \%)$ had also high contribution in the distribution. Most of the patients were married $(70 \%)$, from rural population $(98.5 \%)$ and belonged to nuclear family $(55.5 \%)$. (Table -1$)$

Table - 1 Socio - Demographic characters of the patients in total and according to suicide intentlethality grouping

\begin{tabular}{|c|c|c|c|c|c|c|c|c|c|c|c|}
\hline \multicolumn{2}{|c|}{$\begin{array}{l}\text { SUICIDE INTENT - LETHAITY } \\
\text { GROUPING }(N=200)\end{array}$} & \multicolumn{2}{|c|}{ TOTAL } & \multicolumn{2}{|c|}{$\begin{array}{l}\text { LI-L } \\
\text { GROUP }\end{array}$} & \multicolumn{2}{|c|}{$\begin{array}{c}\text { LI-NL } \\
\text { GROUP }\end{array}$} & \multicolumn{2}{|c|}{$\begin{array}{c}\text { HI- L } \\
\text { GROUP }\end{array}$} & \multicolumn{2}{|c|}{$\begin{array}{l}\mathrm{HI}-\mathrm{NL} \\
\text { GROUP }\end{array}$} \\
\hline AGE (YRS) & $\begin{array}{l}\text { Mean (Std. } \\
\text { deviation) } \\
\text { Median }\end{array}$ & \multicolumn{2}{|c|}{$26.36(9.45)$} & \multicolumn{2}{|c|}{$23.2(4.86)$} & \multicolumn{2}{|c|}{$27.2(10.31)$} & \multicolumn{2}{|c|}{$25.8(9.38)$} & \multicolumn{2}{|c|}{$26.2(8.63)$} \\
\hline \multirow{2}{*}{$\begin{array}{l}\text { GENDER } \\
\text { DISTRIBUTION }\end{array}$} & Male & 99 & $49.50 \%$ & 6 & $6.10 \%$ & 43 & $43.40 \%$ & 35 & $35.40 \%$ & 15 & $15.20 \%$ \\
\hline & Female & 101 & $50.50 \%$ & 6 & $5.90 \%$ & 44 & $43.60 \%$ & 26 & $25.70 \%$ & 25 & $24.80 \%$ \\
\hline \multirow[t]{2}{*}{ RELIGION } & Hindu & 166 & $83 \%$ & 12 & $7.20 \%$ & 70 & $42.20 \%$ & 50 & $30.10 \%$ & 34 & $20.50 \%$ \\
\hline & Muslim & 34 & $17 \%$ & 0 & & 17 & $50.00 \%$ & 11 & $32.40 \%$ & 6 & $17.60 \%$ \\
\hline \multirow{4}{*}{$\begin{array}{l}\text { EDUCATIONAL } \\
\text { STATUS }\end{array}$} & Illiterate & 79 & $39.50 \%$ & 6 & $7.60 \%$ & 38 & $48.10 \%$ & 18 & $22.80 \%$ & 17 & $21.50 \%$ \\
\hline & Primary & 39 & $19.50 \%$ & 0 & & 23 & $59.00 \%$ & 13 & $33.30 \%$ & 3 & $7.70 \%$ \\
\hline & Middle School & 69 & $34.50 \%$ & 6 & $8.70 \%$ & 22 & $31.90 \%$ & 24 & $34.80 \%$ & 17 & $24.60 \%$ \\
\hline & High School & 13 & $6.50 \%$ & 0 & & 4 & $30.80 \%$ & 6 & $46.20 \%$ & 3 & $23.10 \%$ \\
\hline \multirow{7}{*}{$\begin{array}{l}\text { OCCUPATIONAL } \\
\text { STATUS }\end{array}$} & Unemployed & 12 & $6 \%$ & 0 & & 9 & $75.00 \%$ & 3 & $25.00 \%$ & 0 & \\
\hline & Unskilled Worker & 15 & $7.50 \%$ & 0 & & 9 & $60.00 \%$ & 6 & $40.00 \%$ & 0 & \\
\hline & Semi Skilled & 66 & $33 \%$ & 6 & $9.10 \%$ & 37 & $56.10 \%$ & 14 & $21.20 \%$ & 9 & $13.60 \%$ \\
\hline & Worker & 3 & $1.50 \%$ & 0 & & 0 & & 3 & $100.00 \%$ & 0 & \\
\hline & Shop Owner & 13 & $6.50 \%$ & 0 & & 0 & & 7 & $53.80 \%$ & 6 & $46.20 \%$ \\
\hline & Housewife & 71 & $35.50 \%$ & 3 & $4.20 \%$ & 29 & $40.80 \%$ & 17 & $23.90 \%$ & 22 & $31.00 \%$ \\
\hline & Student & 20 & $10 \%$ & 3 & $15.00 \%$ & 3 & $15.00 \%$ & 11 & $55.00 \%$ & 3 & $15.00 \%$ \\
\hline \multirow{3}{*}{$\begin{array}{l}\text { MARITAL } \\
\text { STATUS }\end{array}$} & Married & 140 & $70 \%$ & 6 & $4.30 \%$ & 65 & $46.40 \%$ & 44 & $31.40 \%$ & 25 & $17.90 \%$ \\
\hline & Unmarried & 57 & $28.50 \%$ & 6 & $10.50 \%$ & 22 & $38.60 \%$ & 17 & $29.80 \%$ & 12 & $21.10 \%$ \\
\hline & Widowed & 3 & $1.50 \%$ & 0 & & 0 & & 0 & & 3 & $100.00 \%$ \\
\hline \multirow[t]{2}{*}{ RESIDENCE } & Rural & 197 & $98.50 \%$ & 12 & $6.10 \%$ & 87 & $44.20 \%$ & 58 & $29.40 \%$ & 40 & $20.30 \%$ \\
\hline & Urban & 3 & $1.50 \%$ & 0 & & 0 & & 3 & $100.00 \%$ & 0 & \\
\hline \multirow[t]{2}{*}{ FAMILY TYPE } & Nuclear & 111 & $55.50 \%$ & 6 & $5.40 \%$ & 54 & $48.60 \%$ & 25 & $22.50 \%$ & 26 & $23.40 \%$ \\
\hline & Joint & 89 & $44.50 \%$ & 6 & $6.70 \%$ & 33 & $37.10 \%$ & 36 & $40.40 \%$ & 14 & $15.70 \%$ \\
\hline
\end{tabular}


$29 \%$ patients with suicide attempt had no psychiatric disorder according to DSM IV TR. 25.5\% patients were diagnosed of having Adjustment Disorder, with depressed mood, acute type. Depressive Disorders were present in $23.5 \%$ patients. Total $3 \%$ patients were suffering from Bipolar Mood Disorders. Other diagnoses were Anxiety Disorders
(2.5\%), Schizophrenia (1\%), Intermittent Explosive Disorders (4\%), Alcohol related Disorder (11.5\%). Co-diagnosis of Alcohol Dependence was present in 3.5\% subjects. $99 \%$ patients had no Axis II Disorder according to DSM IV- TR and rest $1 \%$ patients were diagnosed of having Borderline Personality Disorder (Table-2).

Table - 2 Axis I Psychiatric diagnosis of the patients according to DSM IV TR.

\begin{tabular}{|c|c|c|c|c|}
\hline \multicolumn{2}{|r|}{ Axis I Psychiatric Diagnosis (DSM IV TR) } & \multirow{2}{*}{$\begin{array}{c}\text { Frequency } \\
51\end{array}$} & \multirow{2}{*}{$\begin{array}{c}\text { Percent } \\
25.5\end{array}$} & \multirow{2}{*}{$\begin{array}{c}\begin{array}{c}\text { Valid } \\
\text { Percent }\end{array} \\
25.5\end{array}$} \\
\hline Valid & Adjustment Disorder, with Depressed mood, Acute & & & \\
\hline & Major Depressive Disorder, single episode, mild & 6 & 3 & 3 \\
\hline & Major Depressive Disorder, single episode, moderate & 6 & 3 & 3 \\
\hline & Major Depressive Disorder, single, severe, without psychosis & 7 & 3.5 & 3.5 \\
\hline & Major Depressive Disorder, single, severe, with psychosis & 3 & 1.5 & 1.5 \\
\hline & Major Depressive Disorder, recurrent, moderate & 6 & 3 & 3 \\
\hline & Major Depressive Disorder, recurrent, severe, with psychosis & 3 & 1.5 & 1.5 \\
\hline & Major Depressive Disorder, moderate, chronic & 7 & 3.5 & 3.5 \\
\hline & Dysthymic Disorder & 9 & 4.5 & 4.5 \\
\hline & Bipolar I Disorder, Depressed, mild & 1 & 0.5 & 0.5 \\
\hline & Bipolar I Disorder, Depressed, moderate & 2 & 1 & 1 \\
\hline & Bipolar II Disorder, Depressed, mild & 2 & 1 & 1 \\
\hline & Bipolar II Disorder, Depressed, moderate & 1 & 0.5 & 0.5 \\
\hline & Generalized anxiety disorder & 2 & 1 & 1 \\
\hline & Panic disorder, without agoraphobia & 1 & 0.5 & 0.5 \\
\hline & Acute Stress Disorder & 1 & 0.5 & 0.5 \\
\hline & Post traumatic Stress Disorder & 1 & 0.5 & 0.5 \\
\hline & Schizophrenia, paranoid type, chronic & 2 & 1 & 1 \\
\hline & Intermittent Explosive Disorder & 8 & 4 & 4 \\
\hline & Alcohol Dependence & 20 & 10 & 10 \\
\hline & Alcohol Intoxication & 3 & 1.5 & 1.5 \\
\hline & Nil & 58 & 29 & 29 \\
\hline & Total & 200 & 100 & 100 \\
\hline & Co-diagnosis of Alcohol Dependence & 7 & 3.5 & 3.5 \\
\hline
\end{tabular}


A study into the psycho-socio-demographic profile and suicidal intent

Median value of Total Score on Suicidal Intent Scale of the patients was $12(\min -\max =1-23)$. Both male and female subjects also had median value 12 on suicide intent score (Table -3 ).

Table 3 - Suicide intent score of the patients.

TOTAL SUICIDE INTENT SCORE (1 - 23)

Gender

Male $(\mathrm{N}=99)$

Female $(\mathrm{N}=101)$

Total $(\mathrm{N}=200)$
MEAN

11.08

11.69

11.39
MEDIAN

12

12

12
Poisoning $(90.5 \%)$ was the most common mode adopted by the patient, of them organophosphorus poisoning $(79.5 \%)$ was most common. $7.5 \%$ patients attempted suicide by hanging and $1.5 \%$ had history of psychotropic medicine overdose. $87.5 \%$ patients were first suicide attempters presenting to the study. $8 \%$ had previous history of suicide attempt once and $3.5 \%$ patients had previous 3 suicide attempts. Most of the patients $(83 \%)$ had no history of alcohol intake prior to suicide attempt, while $12.5 \%$ patients had history of enough alcohol intake to impair judgment; reality testing and diminish responsibility, prior to suicide attempt and 3\% patients took alcohol intentionally in order to facilitate implementation of attempt. Non Lethal suicide attempt (63.5\%) was commoner than lethal attempt (36.5\%) (Table - 4).

Stressor pattern of the patients, contributing to suicide attempt, showed that $89.5 \%$ patients had problem with primary support group (such as marital problem, interpersonal relationship problem). Economic problem was found in 3\% population (Table -4$)$.

Table 4 : Showing suicide behavioral characters of the subjects in total and according to suicide intentlethality rouping.

\begin{tabular}{|c|c|c|c|c|c|c|c|c|c|c|c|}
\hline \multicolumn{2}{|c|}{$\begin{array}{l}\text { SUICIDE INTENT - LETHAITY } \\
\text { GROUPING }(\mathrm{n}=200)\end{array}$} & \multicolumn{2}{|c|}{ TOTAL } & \multicolumn{2}{|c|}{$\begin{array}{l}\text { LI-L } \\
\text { GROUP }\end{array}$} & \multicolumn{2}{|c|}{$\begin{array}{l}\text { LI-NL } \\
\text { GROUP }\end{array}$} & \multicolumn{2}{|c|}{$\begin{array}{l}\text { HI-L } \\
\text { GROUP }\end{array}$} & \multicolumn{2}{|c|}{$\begin{array}{l}\text { HI-NL } \\
\text { GROUP }\end{array}$} \\
\hline MODE OF SUICIDE & $\begin{array}{l}\text { Poisoning, } \\
\text { Organophosphorus }\end{array}$ & 159 & $79.5 \%$ & 9 & $5.7 \%$ & 78 & $49.1 \%$ & 45 & $28.3 \%$ & 27 & $17.00 \%$ \\
\hline $\begin{array}{l}\text { Lethal- } \\
73(36.5 \%)\end{array}$ & Poisoning, Rat killer & 8 & $4 \%$ & 0 & & 1 & $12.5 \%$ & 2 & $25.0 \%$ & 5 & $62.50 \%$ \\
\hline \multirow{8}{*}{$\begin{array}{l}\text { Non lethal - } \\
127(63.5 \%)\end{array}$} & Poisoning, Lice killer & 3 & $1.50 \%$ & 0 & & 0 & & 3 & $100 \%$ & 0 & \\
\hline & $\begin{array}{l}\text { Poisoning, } \\
\text { Carbolic acid }\end{array}$ & 3 & $1.50 \%$ & 3 & $100 \%$ & 0 & & 0 & & 0 & \\
\hline & Poisoning Sulfuric acid & 1 & $0.50 \%$ & 0 & & 0 & & 1 & $100 \%$ & 0 & \\
\hline & $\begin{array}{l}\text { Poisoning, } \\
\text { Yellow olinder }\end{array}$ & 6 & $3 \%$ & 0 & & 3 & $50.0 \%$ & 0 & & 3 & $50.00 \%$ \\
\hline & $\begin{array}{l}\text { Poisoning, Multiple } \\
\text { Substance }\end{array}$ & 1 & $0.50 \%$ & 0 & & 0 & & 1 & $100 \%$ & 0 & \\
\hline & Hanging & 15 & $7.50 \%$ & 0 & & 2 & $13.3 \%$ & 8 & $53.3 \%$ & 5 & $33.30 \%$ \\
\hline & Self Injury & 1 & $0.50 \%$ & 0 & & 0 & & 1 & $100 \%$ & 0 & \\
\hline & $\begin{array}{l}\text { Psychotropics } \\
\text { Overdose }\end{array}$ & 3 & $1.50 \%$ & 0 & & 3 & $100 \%$ & 0 & & 0 & \\
\hline
\end{tabular}


A study into the psycho-socio-demographic profile and suicidal intent

\begin{tabular}{|c|c|c|c|c|c|c|c|c|c|c|c|}
\hline \multicolumn{2}{|c|}{$\begin{array}{l}\text { SUICIDE INTENT - LETHAITY } \\
\text { GROUPING }(\mathrm{n}=200)\end{array}$} & \multicolumn{2}{|c|}{ TOTAL } & \multicolumn{2}{|c|}{$\begin{array}{l}\text { LI-L } \\
\text { GROUP }\end{array}$} & \multicolumn{2}{|c|}{$\begin{array}{l}\text { LI-NL } \\
\text { GROUP }\end{array}$} & \multicolumn{2}{|c|}{$\begin{array}{l}\text { HI-L } \\
\text { GROUP }\end{array}$} & \multicolumn{2}{|c|}{$\begin{array}{l}\text { HI-NL } \\
\text { GROUP }\end{array}$} \\
\hline PREVIOUS NUMBERS OF & 0 & 175 & $87.5 \%$ & 12 & $6.9 \%$ & 71 & $40.6 \%$ & 55 & $31.4 \%$ & 37 & $21.10 \%$ \\
\hline & 1 & 16 & $8 \%$ & 0 & & 10 & $62.5 \%$ & 3 & $18.8 \%$ & 3 & $18.80 \%$ \\
\hline & 2 & 1 & $0.50 \%$ & 0 & & 1 & $100 . \%$ & 0 & & 0 & \\
\hline & 3 & 7 & $3.50 \%$ & 0 & & 4 & $57.1 \%$ & 3 & $42.9 \%$ & 0 & \\
\hline & 4 & 1 & $0.50 \%$ & 0 & & 1 & $100 . \%$ & 0 & & 0 & \\
\hline \multirow{4}{*}{$\begin{array}{l}\text { HISTORY OF ALCOHOL } \\
\text { INTAKE PRIOR TO SUICIDE } \\
\text { ATTEMPT }\end{array}$} & Absent & 166 & $83 \%$ & 9 & $5.4 \%$ & 77 & $46.4 \%$ & 43 & $25.9 \%$ & 37 & $22.30 \%$ \\
\hline & $\begin{array}{l}\text { Present, Some alcohol } \\
\text { intake }\end{array}$ & 3 & $1.50 \%$ & 0 & & 0 & & 3 & $100 \%$ & 0 & \\
\hline & $\begin{array}{l}\text { Present, Enough } \\
\text { alcohol intake }\end{array}$ & 25 & $12.5 \%$ & 3 & $12 . \%$ & 9 & $36.0 \%$ & 10 & $40.0 \%$ & 3 & $12.00 \%$ \\
\hline & $\begin{array}{l}\text { Present, Intentional } \\
\text { alcohol intake }\end{array}$ & 6 & $3 \%$ & 0 & & 1 & $16.7 \%$ & 5 & $83.3 \%$ & 0 & \\
\hline \multirow[t]{4}{*}{ STRESSOR } & $\begin{array}{l}\text { Problem with primary } \\
\text { support group }\end{array}$ & 179 & $89.5 \%$ & 12 & $6.7 \%$ & 83 & $46.4 \%$ & 53 & $29.6 \%$ & & $17.30 \%$ \\
\hline & Economic problem & 6 & $3 \%$ & 0 & & 3 & $50.0 \%$ & 0 & & 3 & $50.00 \%$ \\
\hline & Occupational problem & 3 & $1.50 \%$ & 0 & & 0 & & 0 & & 3 & $100 . \%$ \\
\hline & Not found & 12 & $6 \%$ & 0 & & 1 & $8.30 \%$ & 8 & $66.7 \%$ & 3 & $25.00 \%$ \\
\hline
\end{tabular}

LI-L = Low intent - Lethal, LI- NL = Low intent - Non lethal, HI-L = High intent - Lethal, HI- NL = High intent - Non lethal,

Categorization by Suicide Intent - The first grouping was done by taking suicide intent as the dimension. Patients were grouped in high suicide intent and low suicide intent group by taking cut off point 12 on Total Score on Suicidal Intent Scale. Median value of Total Score on Suicidal Intent Scale of the both male and female patients was 12. So, High suicide intent - Total Score on Suicidal Intent Scale $=12$ or more and Low suicide intent - Total Score on Suicidal Intent Scale = less than 12. The grouping was statistically significant $(\mathrm{P}<0.05)$ on the distribution of age $(P=0.000)$, sex $(P=0.000)$, religion $(\mathrm{P}=0.04)$, occupational status $(\mathrm{P}=0.000)$, lethality of suicide attempt $(\mathrm{P}=0.000)$,

Psychiatric disorder on Axis I according to DSM IV TR diagnosis $(\mathrm{P}=0.000)$, mode of suicide attempt $(P=0.002)$ and stressor $(P=0.007)($ Table -5$)$.

\section{Categorization $b$ y Suicide Intent and Lethality of} suicide attempt - The second grouping was done by taking suicide intent and lethality of suicide attempt as the dimension. Four groups emerged 1)Lowintent-Lethalgroup, 2) Lowintent-NonLethal group, 3) High intent-Lethal group, 4) High intentNon Lethal group. The grouping was statistically significant $(\mathrm{P}<0.05)$ on the distribution of age ( $P=0.000)$, education $(P=0.049)$, occupational status $(P=0.000)$, marital status $(P=0.016)$, family type $(\mathrm{P}=0.000)$, Psychiatric disorder on Axis I according to DSM IV TR diagnosis $(P=0.000)$, mode of suicide attempt $(\mathrm{P}=0.000)$, history of alcohol intake prior to suicide attempt and stressor $(\mathrm{P}=0.001)($ Table - 5)

\section{COMPARISON OF THE TWO PROCEDURES OF GROUPINGS -}

When the above two procedure were statistically compared, four groupings was found more significant than the previous two groupings. The distribution of education, marital status, family type, history of alcohol intake prior to suicide attempt became statistically significant (Table - 5). 
A study into the psycho-socio-demographic profile and suicidal intent

Table - 5 : Showing the group characteristics and respective $P$ values.

\begin{tabular}{l|c|c|}
\multirow{2}{*}{ Psycho-Socio-Demographic Character } & \multicolumn{2}{|c|}{ P Value } \\
\cline { 2 - 3 } Age & Grouping by Suicide Intent & Grouping by Suicide Intent - Lethality \\
Sex & 0 & 0 \\
Religion & 0 & 0.282 \\
Education & 0.04 & 0.389 \\
Occupation & 0.08 & 0.049 \\
Marital Status & 0 & 0 \\
Residence & 0.22 & 0.016 \\
Family Type & 0.084 & 0.074 \\
Axis I Psychiatric Diagnosis (DSM IVTR) & 0.097 & 0.04 \\
Axis II Psychiatric Diagnosis (DSM IVTR) & 0 & 0 \\
Mode of Suicide Attempt & 0.151 & 0.453 \\
Previous history of Suicide Attempt & 0.002 & 0 \\
Alcohol intake prior to Suicide attempt & 0.465 & 0.719 \\
Stressor & 0.116 & 0.016 \\
\hline
\end{tabular}

\section{DISCUSSION :}

This study found that majority of the suicide attempts were in the age group of $20-30$ yrs. Male had higher mean and median age than female population. This supports previous studies on suicide, as suicide is more common in younger adults. Females (50.5\%) slightly outnumbered males (49.5\%) with $\mathrm{M}: \mathrm{F}$ $=(0.98: 1)$. This is because in rural India females are more subjected to family violence and marital problem than western countries. Hindus (83\%) were majority population attempting suicide as they are major religious groups in India. Most of the patients were housewives $(35.5 \%)$, next was semi skilled worker (33\%). Notably students $(10 \%)$ had also high contribution in the distribution. This reflects that marital problem, family violence in Indian women, occupational problem in semiskilled worker, and growing academic pressure on students contributed to higher suicide rate in this population. Indian men and women have early age of marriage, which explains high rate of suicide attempt in married population $(70 \%)$. Our study supported findings of previous studies that nuclear family (55.5\%) has higher suicide rate. Most of the patient attempted a non lethal suicide attempt (63.5\%). It points towards an impulsivity and lack of knowledge about lethality of attempt in rural Indian population.
Majority of the patients had no psychiatric disorder $(29 \%)$ during suicide attempt. Severe mental illness seems to be related to suicide when the rates are low (i.e. 10 per 100000 population) but does not seem to contribute significantly when the suicide rates are high, as in India, where social, economic and cultural factors play a much greater part. [12] $25.5 \%$ patients were diagnosed of having Adjustment Disorder, with depressed mood, acute type. Depressive Disorders were present in $23.5 \%$ patients. Previous studies also support our findings. Alcohol use disorders were found in $11.5 \%$ population, reflecting association between alcoholics and suicidal behavior. Personality disorder, as it is not common in India, was found only in $1 \%$ suicide attempters.

Poisoning $(90.5 \%)$ was the most common mode adopted by the patient, of them organophosphorus poisoning (79.5\%) was most common. $7.5 \%$ patients attempted suicide by hanging and $1.5 \%$ had history of psychotropic medicine overdose. Previous study from rural India also got similar findings as organophosporusis easily available so readily taken as the most common substance for poisoning. $12.5 \%$ patients had previous suicide attempt, reflecting a high rate of repeating the procedure. $17 \%$ patients had history of alcohol intake prior to suicide attempt, mostly severe enough to impair judgment about 
the stressor and suicide attempt, making it more impulsive. Problem with primary support groups $(89.5 \%)$ was found in most of the patient, reflecting interpersonal problem with parents, close relations and marital problem.

Categorization by Suicide Intent - High intent group is distinct from low intent group as it had higher median age of population, more male distribution, Hindu religiosity, higher educational status, mostly of housewife and student population, high lethality of suicide attempt, diagnosis of a psychiatric disorder, hanging and poisoning as a mode of attempt and mostly related to problem with primary support group, occupational problem as a stress factor.

Categorization by Suicide Intent and Lethality of suicide attempt - Low intent - Non lethal group is distinct from rest other group as it had mostly illiterate population, majority of semi skilled workers and of housewives, married patient, nuclear family type, no psychiatric diagnosis, poisoning as a mode of attempt, absence of alcohol intake prior to suicide attempt and problem with primary support group as a contributing stress factor.

Comparison of the two procedures of grouping With taking suicide intent and lethality of attempt as two determining dimensions for suicide attempt, the second procedure of four class grouping showed inclusion of education, marital status, history of alcohol intake prior to suicide attempt and giving more significance on residence, mode of suicide attempt, stressor as factors playing role in suicide behavior within groups.

Separating human distress from depression is difficult. ${ }^{13}$ The depression seen in the community is often viewed as a result of personal and social stress, lifestyle choices or habitual maladaptive patterns of behavior. Consequently, the general population and general physicians often hold psychological and social models for depression and for suicide. Psychiatrists, with their biomedical frameworks, on the other hand, argue for disease models for these conditions. $^{14}$
They transfer the disease halo reserved for melancholiaandseverementalillnesstoallpsychiatric diagnoses. Epidemiological studies in general and on suicide in particular use diagnostic instruments that do not evaluate stress-related conditions ${ }^{15,16}$ and fail to address adjustment disorders. ${ }^{17,} 18$ One study supports the view that the majority of people in India who kill themselves do not have a severe mental disorder. Qualitative investigations from the region have documented a widespread belief in the population that suicide is an option when faced with severe personal distress. ${ }^{9}$ A previous case-control study on risk factors for suicide in India, although documenting the association between suicide and psychopathology, highlighted its association with adverse life events. ${ }^{19}$ Qualitative data suggest that many in the general population view suicide as an option when faced with apparently insoluble personal difficulties and misfortune. ${ }^{20}$ Our study supported the view that in India majority of the suicide attempters had no psychiatric diagnosis at the time of suicide attempt. It is the culture which determines the coping mechanism style during acute stress or conflict. Previous studies found that suicide intent scores had been shown to be related to the potential lethality of the method of self-harm. ${ }^{21,22}$ We also found that lethality of attempt was determined by suicide intent in majority of cases $(\mathrm{P}=0.000)$.

Carroll-Ghosh ${ }^{22}$ make a distinction between those who 'attempt' and those who 'complete' suicide in that those who attempt are more likely to be females, under 35 years of age, use low means of lethality (e.g. wrist laceration), do it in a setting where there are high chances of rescue, and usually suffer from adjustment disorder or personality disorder. In comparison those who complete suicide are usually males, over 60 years of age, use high means of lethality (e.g. firearms, hanging), do it in a setting where there are low chances of rescue and usually suffer from mood disorder and substance abuse. Our study also gave a distinct group of High intent population,those bear the same character as that of 'completed' suicide by Carroll-Ghosh. ${ }^{23}$ 
From the previous studies it is evident that there are confusions among researchers about the dimension, whether it should be suicidal intent or lethality of suicide attempt or both should be considered to define the characteristics of Deliberate Self Harm (DSH) group. Some researchers made the distinction based on suicidal intent, completely ignoring the lethality of attempt in view of the fact that lethality was proportional to suicidal intent. Others made the distinction or gave emphasis more on lethality of suicidal attempt. But the questions that arise are -1) If a person with suicide attempt has high suicide intent but commits non lethal attempt, not sufficient to end one's life, in which group he/she will be clubbed, in Failed suicide or in DSH?, 2) If a person with suicide attempt has low suicide intent but commits lethal attempt, sufficient to end one's life, but survived then in which group he/she will be clubbed, in DSH or in Failed suicide?

Beck and his colleagues had view of the first question and tried to solve the problem by virtue of 'knowledge of lethality'. But again the question comes that if a person with low suicide intent complete the act by lethal attempt, even after that whether we should clubbed the person in the group of attempters or completers. From the consideration of Beck's view we are not able to give the answer. The above mentionedperson is a completer rather than attempter. So we have to take consideration of both suicide intent and lethality of attempt as determining dimensions to make distinctive groups of suicide attempting people and to define the characteristics of DSH group. If one makes hypothetically four distinctive groups, combining both suicide intent and lethality of attempt, there comes - 1) High intent - lethal, 2) High intent - non lethal, 3) Low intent - lethal, 4) Low intent- non lethal groups. Our study proved that it is better to consider both suicide intent and lethality of suicide attempt, as determining dimensions in categorization or grouping of suicidal patients and then only we can correctly define the DSH group in respect of psychosocio-demographic profile.

\section{CONCLUSION :}

Previous attempts to classify suicidal patients by using suicide intent as determining dimension led many of the suicide attempters to be falsely categorized in either group of Failed suicide and DSH group. But after taking both the suicide intent and lethality of suicide attempt as determining dimensions of suicide, 'Deliberate Self Harm' or parasuicide, or, pseudosuicide, group is correctly classified and defined by their psycho-sociodemographic profile and those belong to the 'Low intent-Non Lethal group'.

\section{LIMITATIONS :}

1) It was not possible to include all self-harm patients presenting to the general hospital during the study period.

2) Follow-up information was not available for the patients in the study sample.

3) Some suicides might have been missed owing to their non attending psychiatric department out of stigma.

\section{REFERENCES :}

1) Vijaykumar L. Indian Journal of Psychiatry 2007; 49(2) : 81-84.

2) Joseph A, Abraham S, Muliyil JP, George K, Prasad J, Minz $S$, et al. Suicide rates in rural India using verbal autopsies, 1994-9. BMJ 2003; $326: 1121-2$.

3) Vijayakumar L, John S, Pirkis J, Whiteford H. Suicide in developing countries 2 : Risk factors. Crisis 200; 26 : 112-9.

4) Latha KS, Bhat SM, D Souza P. Suicide attempters in a general hospital unit in India : Their sociodemographic and clinical profile-emphasis on crosscultural aspects. Acta Psychiatr Scand 1996; 94 : 26-30.

5) Jain V, Singh H, Gupta S.C, Kumar S.A study of hopelessness, suicidal intent and dpression in cases of attempted suicide. Indian J Psychiatry 1999; 41(2) : 122-130.

6) Stengel E. Enquiries into attempted suicide. Proc R Soc Med 1952; 45 : 613-20.

7) Kessel N, Grossman G. Suicide in alcoholics. Br Med J 1965; ii : 1671-2.

8) Morgan HG. Death wishes? The understanding and management of deliberate self harm. Chichester : Wiley; 1979. 
9) Beck A, Davis IH, Frederick C, et al: Classification and nomenclature, in Suicide Prevention in the Seventies. Edited by Resnik H, Hathorne B. Washington, DC, US Government Printing Office, 1973, 7-12.

10) Stengel E : Presidential address, in Proceedings, 6th International Conference on Suicide Prevention. Edited by Litman RE. Ann Arbor, Mich, Edwards Brothers, 1972, 18-3 I.

11) Brown, G.K., Henriques, G.R., Sosdjan, D., Suicide intent and accurate expectations of lethality : predictors of medical lethality of suicide attempts. Journal of Consulting and Clinical Psychology, 2004; $72: 1170-1174$

12) Manoranjitham S.D, Rajkumar A.P, Thangadurai. P, Prasad J, Jayakaran R, Jacob K.S. Risk factors for suicide in rural south India. The British Journal of Psychiatry 2010; 196 : 26-30.

13) Heath $I$. There must be limits to the medicalisation of human distress. BMJ 1999; $318: 439-40$.

14) Kessler D, Lloyd K, Lewis G, Gray DP. Cross sectional study of symptom attribution and recognition of depression and anxiety in primary care. BMJ 1999; $318: 436-9$.

15) Lewis G, Pelosi A, Araya R, Dunn G. Measuring psychiatric morbidity in the community : a standardised interview for use by lay interviewers. Psychol Med 1992; 22 : 465-86.

16) Robins LN, Wing J, Wittchens HU, Helzer JE, Babor TF, Burke J, et al. The Composite International Diagnostic
Interview : an epidemiological instrument suitable for use in conjunction with different diagnostic systems in different cultures. Arch Gen Psychiatry 1988; 45 : 1069-77.

17) Portzky G, Audenaert K, van Heeringen K. Adjustment disorder and the course of the suicidal process in adolescents. J Affect Disord 2008; 87 : 265-70.

18) Casey P, Dowrick C, Wilkinson G. Adjustment disorders: fault line in the psychiatric glossary. Br J Psychiatry 2001; 179 : 479-81.

19) Manoranjitham $S$, Charles $H$, Saravanan $B$, Jayakaran R, Abraham S, Jacob KS. Perceptions about suicide : a qualitative study from southern India. Natl Med J India $2007 ; 20: 176-9$.

20) Vijayakumar L, Rajkumar S. Are risk factors for suicide universal? A case - control study in India. Acta Psychiatr Scand 1999; 99 : 407-11.

21) Hamdi E., Amin T. \& Mattar, T. Clinical correlates of intent in attempted suicide. Acta Psychiatrica Scandinavica. 1991; 83 : 406-411.

22) Haw, C., Hawton, K., Houston, K. Correlates of relative lethality and suicidal intent among deliberate self-harmpatients. Suicide and Life-Threatening Behavior. 2003; 33 : 353-364.

23) Carroll-Ghosh T, Victor BS, Bourgeors JA. Suicides. In : Hales RE, Yudof Sky SG (eds). Textbook of clinical psychiatry, 4th ed. Washington, DC : American Psychiatric Publishing 2003; 1457-83. 